\title{
The Role of the PDZ Protein GIPC in Regulating NMDA Receptor Trafficking
}

\author{
Zhaohong Yi, ${ }^{1}$ Ronald S. Petralia, ${ }^{1}$ Zhanyan Fu, ${ }^{2}$ Catherine Croft Swanwick, ${ }^{1}$ Ya-Xian Wang, ${ }^{1}$ Kate Prybylowski, ${ }^{1}$ \\ Nathalie Sans, ${ }^{1}$ Stefano Vicini, ${ }^{2}$ and Robert J. Wenthold ${ }^{1}$ \\ ${ }^{1}$ Laboratory of Neurochemistry, National Institute on Deafness and Other Communication Disorders, National Institutes of Health, Bethesda, Maryland \\ 20892, and ${ }^{2}$ Department of Physiology and Biophysics, Georgetown University Medical Center, Washington, DC 20007
}

The NMDA receptor is an important component of excitatory synapses in the CNS. In addition to its synaptic localization, the NMDA receptor is also present at extrasynaptic sites where it may have functions distinct from those at the synapse. Little is known about how the number, composition, and localization of extrasynaptic receptors are regulated. We identified a novel NMDA receptor-interacting protein, GIPC (GAIP-interacting protein, $\mathrm{C}$ terminus), that associates with surface as well as internalized NMDA receptors when expressed in heterologous cells. In neurons, GIPC colocalizes with a population of NMDA receptors on the cell surface, and changes in GIPC expression alter the number of surface receptors. GIPC is mainly excluded from the synapse, and changes in GIPC expression do not change the total number of synaptic receptors. Our results suggest that GIPC may be preferentially associated with extrasynaptic NMDA receptors and may play a role in the organization and trafficking of this population of receptors.

Key words: NMDA receptor; extrasynaptic receptor; PDZ; GIPC; plasticity; endocytosis

\section{Introduction}

The NMDA receptor is present at most glutamatergic synapses in the mammalian CNS where it plays a key role in synaptic transmission, synaptic plasticity, and synapse development. Although the NMDA receptor is considered to be a relatively stable molecule at the synapse, compared with the AMPA receptor, several studies have shown that a number of conditions quickly lead to significant changes in the number of synaptic NMDA receptors. Activation of type 1 metabotropic receptors causes a rapid internalization of synaptic NMDA receptors (Snyder et al., 2001), and some forms of long-term potentiation and long-term depression involve changes in synaptic NMDA receptors (Bashir et al., 1991; Berretta et al., 1991; O’Connor et al., 1994; Grosshans et al., 2002; Montgomery and Madison, 2002; Harney et al., 2006). Furthermore, synaptic NMDA receptors appear to constitutively recycle and exchange with cytoplasmic and extrasynaptic receptors (Roche et al., 2001; Tovar and Westbrook, 2002; Groc et al., 2004; Prybylowski et al., 2005; Groc et al., 2006). Changes in synaptic NMDA receptors are likely to involve clathrin-dependent endocytosis and the addition of new and recycled receptors to the cell

\footnotetext{
Received July 17, 2007; revised Aug. 31, 2007; accepted Sept. 4, 2007.

This work was supported by the National Institute on Deafness and Other Communication Disorders Intramural Research Program. We thank Drs. M. Chao and V. Setaluri for antibodies to GIPC, Dr. R. Lefkowitz for the myc-GIPC construct, and Dr. P. Osten for the HA-GluR1 construct. We thank members of the Laboratory of Neurochemistry for their helpful comments on this manuscript.

Correspondence should be addressed to Dr. Robert J. Wenthold, National Institute on Deafness and Other Communication Disorders, National Institutes of Health, Building 50, Room 4140, Bethesda, MD 20892. E-mail: wenthold@nidcd.nih.gov.

N. Sans's present address: Equipe AVENIR/ENI-Net, Cellular and Molecular Neurobiology, Centre de Recherche Francois Magendie U862, Institut National de la Sante et de la Recherche Medicale, 33077 Bordeaux Cedex, France. DOI:10.1523/JNEUROSCI.3252-07.2007

Copyright $\odot 2007$ Society for Neuroscience $\quad$ 0270-6474/07/2711663-13\$15.00/0
}

surface by exocytosis (Roche et al., 2001; Lavezzari et al., 2004; Scott et al., 2004; Montgomery et al., 2005; Prybylowski et al., 2005; Perez-Otano et al., 2006).

NMDA receptors are also present at extrasynaptic sites where they may have functions distinct from those at the synapse (Vanhoutte and Bading, 2003). Extrasynaptic receptors have more NR2B, whereas synaptic receptors are enriched in NR2A (Rumbaugh and Vicini, 1999; Tovar and Westbrook, 1999; Thomas et al., 2006). Synaptic and extrasynaptic NMDA receptors are regulated differently; for example, the number of extrasynaptic receptors is increased by overexpression of NR2 subunits, whereas the number of synaptic receptors is not altered (Barria and Malinow, 2002; Prybylowski et al., 2002).

The NMDA receptor interacts with several PDZ [postsynaptic density-95 (PSD-95)/Discs large/zona occludens-1] proteins including all four members of the PSD-95 family of proteins, CIPP (channel-interacting PDZ domain protein), MALS (mammalian LIN-seven protein), and MAGI1 [membrane-associated guanylate kinase (MAGUK) with inverted orientation] (Wenthold et al., 2003). These and other PDZ proteins are likely candidates for proteins that may play a role in regulating trafficking of NMDA receptors. In our two-hybrid analysis of binding partners of the cytoplasmic domains of NR2 subunits, we have identified the PDZ protein GIPC1 (GAIP-interacting protein, C terminus; also known as SEMCAP-1, GLUT1CBP, TIP-2, synectin, NIP-1) (De Vries et al., 1998; Rousset et al., 1998; Bunn et al., 1999; Cai and Reed, 1999; Wang et al., 1999; Gao et al., 2000). GIPC has a single PDZ domain and has been shown to play a role in the trafficking of several membrane proteins. It is widely expressed and, in neurons, is found throughout the cell including both presynaptic and postsynaptic locations (Jeanneteau et al., 2004a; Yano et al., 2006). We find that GIPC is localized predominantly outside of 
the synapse and changes in GIPC expression alter the number of NMDA receptors on the cell surface.

\section{Materials and Methods}

DNA constructs. GIPC full-length cDNA, GIPC-N+PDZ (amino acids 1-225), GIPC-C+PDZ (amino acids 125-333), GIPC-N (amino acids 1-124), GIPC-C (amino acids 226-333), and GIPC-PDZ (amino acids 226-333) were amplified from the mouse brain cDNA library (Clontech, Palo Alto, CA) using PCR and subcloned into the mammalian expression vector pEGFP-C2 (Clontech), yeast two-hybrid prey vector pACT2 (Clontech), and bacterial expression vector pGEX4T1. Rat mycGIPC was a generous gift from Dr. R. Lefkowitz (Howard Hughes Medical Institute, Durham, NC). The mutation LGL/AAA in the PDZ domain (amino acids 143-145) was generated by site-directed mutagenesis (QuickChange Site-Directed Mutagenesis kit; Stratagene, La Jolla, CA). NR2B C terminus (amino acids 1315-1482) was amplified using PCR and subcloned into yeast two-hybrid bait vector pGBKT7 (Clontech). TacNR2B (amino acids 1315-1482) and TacNR2A (amino acids 13041461) were described previously (Roche et al., 2001). Flag-NR2B, mycNR2B, and myc-NR2A (full-length NR2B or NR2A constructs containing an $\mathrm{N}$-terminus extracellular flag or myc epitope) have been described previously (Prybylowski et al., 2005). HA-GluR1 was a generous gift from Dr. P. Osten (Max-Planck Institute, Heidelberg, Germany). The mutations of NR2B- $\Delta$ 7aa and NR2B-V1482A were generated by site-directed mutagenesis using pGBKT7-NR2B, TacNR2B, or flag-NR2B as the template. For small interfering RNA (siRNA) knockdown of GIPC, oligonucleotides containing nucleotides $240-258$ or nucleotides $399-417$ of rat GIPC cDNA (accession number NM_053341; critical 19 nt sequence, GGAGCTGTACGGCAAGATC or GGTGGAAGTATTCAAGTCT) were subcloned downstream of the human $\mathrm{H} 1$ promoter in the vector pSUPER.gfp/neo (Oligoengine, Seattle, WA) fused with green fluorescent protein (GFP). The empty vector expressing GFP only without siRNA sequence was used as a control in experiments.

Antibodies. GIPC antibodies used for immunoprecipitation and immunocytochemistry were generated by immunizing rabbits with the fulllength GST-GIPC fusion protein. This antiserum was used at 1:5000 for Western blot and 1:2000 for immunostaining in neurons. The following mouse monoclonal antibodies were used: anti-Tac (1:1000) for surface and intracellular immunostaining and 9E10 anti-myc (1:200) for surface and intracellular staining in neurons (both obtained from hybridoma cells from American Type Culture Collection, Manassas, VA); antihemagglutinin (HA) (1:1000) for surface staining of neurons (clone 12CA5; Roche, Indianapolis, IN); anti-PSD-95, 1:200 for immunofluorescence and 1:1000 for Western blot (Affinity Bioreagents, Golden, CO); anti-bassoon (1:100) for immunofluorescence (Stressgen, Victoria, British Columbia, Canada); anti-NR1 (clone 54.2), 1:500 for immunofluorescence and 1:5000 for Western blot, and anti-NR2B, 1:100 for Western blot (Transduction Laboratories, Lexington, KY). Rabbit polyclonal antibodies used were as follows: anti-flag (1:200) for surface labeling in neurons (Sigma, St. Louis, MO), anti-myc (1:500) for immunofluorescence in COS cells (Upstate Biotechnology, Lake Placid, NY), and antiGFP, 1:1000 for immunofluorescence and 1:5000 for Western blot (Chemicon, Temecula, CA). A guinea pig SAP102 antibody, 1:500 for immunofluorescence and 1:2000 for Western blot, was made using the first 119 aa residues, as described previously (Sans et al., 2000). All secondary antibodies were used at 1:5000 for Western blot (Jackson ImmunoResearch, West Grove, PA) and at 1:1000 for immunofluorescence (Invitrogen, Eugene, OR).

Yeast two-hybrid screening. The distal portion of the NR2B C terminus (amino acids 1315-1482) was cloned into vector pGBKT7 in-frame with the DNA binding domain of GAL4. Yeast two-hybrid screening was performed as described in the Clontech protocol. Briefly, AH109 cells expressing GAL4-NR2B were combined with Y187 cells expressing the adult mouse brain cDNA library (Clontech). The mating mixture was plated on synthetic defined plates deficient in adenine, tryptophan, leucine, and histidine. Seven days after transformation, 72 colonies tested $\mathrm{His}^{+} \mathrm{LacZ}^{+}$. The library plasmids from positive colonies were rescued and sequenced. Among the positive clones, two independent clones containing the full-length GIPC sequence were isolated.
Yeast two-hybrid protein interaction assay. The interaction between NR2B C terminus and GIPC was investigated with a yeast two-hybrid interaction assay. NR2B C terminus (amino acids 1315-1482) or mutations of NR2B- $\Delta 7$ aa and NR2B-V1482A in the GAL4 binding domain vector and different GIPC truncations in the GAL4 activation domain vector were cotransformed into yeast AH109. For each transformation, yeasts were first plated onto synthetic defined plates containing histidine but lacking tryptophan and leucine. The colonies were then transferred onto synthetic defined plates deficient in adenine, tryptophan, leucine, and histidine but containing $\alpha$-GAL to measure the direct interaction. Nutrition selection and blue color were used as a measure of direct interaction.

Immunoprecipitation and Western blotting analysis. Coimmunoprecipitation experiments were performed on 35-d-old Sprague Dawley rat hippocampus after sodium deoxycholate (DOC) solubilization. Tissue was homogenized with a polytron in $50 \mathrm{~mm}$ Tris- $\mathrm{HCl}, \mathrm{pH} 7.4$, containing a protease inhibitor mixture. Membranes were sedimented by centrifugation at $100,000 \times g$ for $30 \mathrm{~min}$ at $4^{\circ} \mathrm{C}$, and the membrane fraction was resuspended in $50 \mathrm{~mm}$ Tris- $\mathrm{HCl}$ and $1 \mathrm{~mm}$ EDTA, pH 9.0. DOC was added to a final concentration of $1 \%$. Solubilization was performed at $37^{\circ} \mathrm{C}$ for $45 \mathrm{~min}$, followed by centrifugation at $100,000 \times \mathrm{g}$ for $60 \mathrm{~min}$ at $4^{\circ} \mathrm{C}$. Triton X-100 was added to a final concentration of $0.1 \%$, and the supernatant was dialyzed for $4 \mathrm{~h}$ against $50 \mathrm{~mm}$ Tris, $\mathrm{pH}$ 7.5, containing $0.1 \%$ Triton X-100. Then the DOC lysate was incubated with preimmune serum or GIPC antiserum immobilized on protein A-Sepharose for $2 \mathrm{~h}$. After washing with PBS containing $0.1 \%$ Triton X-100 three times, the Sepharose was boiled in $2 \times$ SDS sample buffer and loaded onto $4-20 \%$ Tris-glycine gels (Invitrogen, Carlsbad, CA). Proteins were transferred to polyvinylidine difluoride membrane (Millipore, Bedford, MA), incubated with primary and secondary antibodies, and detected with ECL using x-ray films (Eastman Kodak, Rochester, NY).

Transfection and immunofluorescence of COS cells. COS and HeLa cells used for transient transfections were maintained in DMEM supplemented with $10 \%$ fetal calf serum (Invitrogen) and 2 mM glutamine and kept at $37^{\circ} \mathrm{C}$ and $5 \% \mathrm{CO}_{2}$. Cells were plated $50-80 \%$ confluent in sixwell dishes for $24 \mathrm{~h}$. On the day of transfection, $2 \mu \mathrm{g}$ of DNA of TacNR2B and myc-GIPC were cotransfected into cells using LipoFectamine2000 (Invitrogen) for $3 \mathrm{~h}$. Then the cells were cultured in fresh medium for an additional $20 \mathrm{~h}$ for staining.

For intracellular staining, transfected cells were fixed with $4 \%$ paraformaldehyde for 15 min, washed, permeabilized in PBS containing $0.1 \%$ Triton X-100 for $5 \mathrm{~min}$, and blocked in 10\% normal goat serum (NGS) in PBS for $1 \mathrm{~h}$. Cells were incubated with a primary antibody in PBS containing 3\% NGS for $1 \mathrm{~h}$, washed, and incubated with secondary antibodies for $30 \mathrm{~min}$ in $3 \% \mathrm{NGS} / \mathrm{PBS}$. For surface labeling, cells were incubated with Tac monoclonal antibodies for $1 \mathrm{~h}$ on ice, washed with PBS, and fixed in 4\% paraformaldehyde in PBS for $15 \mathrm{~min}$, and secondary antibodies were applied for $30 \mathrm{~min}$ before permeabilization. To measure internalization, cells were incubated with Tac monoclonal antibodies for $1 \mathrm{~h}$ on ice to label surface receptors. After washing with PBS, the cells were returned to $37^{\circ} \mathrm{C}$ for 5 or $30 \mathrm{~min}$ for internalization. The cells were chilled immediately by using ice-cold PBS and exposed to $0.5 \mathrm{M} \mathrm{NaCl} / 0.2 \mathrm{M}$ acetic acid for $4 \mathrm{~min}$ on ice to remove the remaining label from the surface. The cells were washed with PBS, fixed in $4 \%$ paraformaldehyde in PBS for $15 \mathrm{~min}$, washed with PBS, and permeablized in $0.1 \%$ Triton $\mathrm{X}-100$ for $5 \mathrm{~min}$. The coverslips were then incubated with FITC- or Cy3-conjugated anti-mouse secondary antibody for $30 \mathrm{~min}$.

For colocalization analysis in COS cells, five areas of $10 \times 10 \mu \mathrm{m}$ were selected from each cell. In each area, the number of internalized TacNR2B or mutant puncta overlapping with myc-GIPC and the total number of internalized TacNR2B or mutant puncta were counted. Value of colocalization was defined as the percentage ratio of these two numbers. Measurements from five areas were first grouped and averaged per cell. Means from different cells were averaged to obtain a final mean \pm SEM. Statistical significance between two data sets was calculated using a Student's $t$ test.

Hippocampal cultures and immunofluorescence. All experiments involving animals were performed according to the National Institutes of Health guidelines. Hippocampal neurons were cultured as described pre- 
viously (Sans et al., 2003). Briefly, hippocampi were dissected from embryonic day 18 Sprague Dawley rats, dissociated in $0.25 \%$ trypsin, and incubated with $0.01 \%$ DNase. Dispersed neurons were plated onto polylysine/fibronectin-coated glass coverslips at a density of 250,000 cells per well of a six-well dish in Neurobasal medium containing 2\% FBS and 2\% B27 supplement. The culture media were changed to neurobasal medium plus B27 after $3 \mathrm{~d}$ in vitro (DIV). The neurons were grown for $10-15 \mathrm{~d}$ and transfected with plasmids using LipoFectamine2000 (Invitrogen).

For surface staining, transfected neurons were incubated with antibodies to flag or myc in Neurobasal medium for $45 \mathrm{~min}$ at room temperature to label surface-expressed NMDA receptors. The antibodies were removed, and the neurons were washed three times with Neurobasal medium. The cells were fixed with $4 \%$ paraformaldehyde in PBS for 15 min and incubated with rhodamine-conjugated anti-rabbit or antimouse secondary antibodies.

For internalization assays, after surface labeling with a primary antibody, the cells were returned to conditioned medium at $37^{\circ} \mathrm{C}$ for a $30 \mathrm{~min}$ incubation to allow internalization. Cells were fixed and labeled with a rhodamine-conjugated secondary antibody (surface label). Cells were then washed in PBS and permeablized in $0.1 \%$ Triton X-100 in PBS for 5 min. After a 60 min preincubation with $10 \%$ NGS, the cells were incubated with far red-conjugated secondary antibodies for $30 \mathrm{~min}$ to label the internalized receptor pool.

Immunocytochemistry on brain sections. Preimbedding light microscope methods for immunofluorescence and immunoperoxidase labeling of rat brain sections have been described previously (Petralia et al., 1997). Briefly, postnatal day 35 (P35) Sprague Dawley rats were anesthetized with a 1:1 mixture of ketamine and xylazine, perfused, and postfixed in $4 \%$ paraformaldehyde, and $50 \mu \mathrm{m}$ parasagittal brain slices were incubated in GIPC serum (1:500 for immunoperoxidase; 1:2000 for immunofluorescence and processed for immunoperoxidase labeling using the Vectastain ABC kit and DAB peroxidase substrate kit (Vector Laboratories, Burlingame, CA), or were labeled with secondary antibodies for immunofluorescence. Moderate labeling was seen in neurons throughout the brain (data not shown) as described by others (Jeanneteau et al., 2004a; Yano et al., 2006). In control sections, preimmune serum was used at the same dilution, and labeling was absent. Double-labeling immunofluorescence with GIPC and NR1 also was done, and evidence was seen of colocalization in dendrites (our unpublished data). Some immunoperoxidase-labeled sections were processed further for electron microscopy, including fixation in osmium tetroxide, dehydration, and embedding in epon, as described previously (Petralia et al., 1997). For immunogold labeling, sections of the rat hippocampus were processed as described previously (Sans et al., 2000). Rats were perfused with $4 \%$ paraformaldehyde plus $0.5 \%$ glutaraldehyde, frozen sections were freeze-substituted in a Leica (Vienna, Austria) AFS system and infiltrated with Lowicryl HM-20 resin, and thin sections were labeled with a primary antibody followed by immunogold (Ted Pella, Redding, CA). Primary antibodies for immunogold labeling for GIPC included one provided by Dr. V. Setaluri (University of Wisconsin, Madison, WI) (1:251:50) (Liu et al., 2001), another provided by Drs. H. Yano and M. V. Chao (Skirball Institute of Biomolecular Medicine, New York University School of Medicine, New York, NY) (1:300) (Yano et al., 2006), and one purchased from Proteus Biosciences (Ramona, CA; $10 \mu \mathrm{g} / \mathrm{ml}$ ) (Dance et al., 2004). Control sections lacked the primary antibody and showed only rare gold. PSD-95 monoclonal antibody was purchased from BD Biosciences (Franklin Lakes, NJ) (Sans et al., 2000), and an NR1 monoclonal antibody (clone 54) (Sucher et al., 1993) was used in double labeling with GIPC antibody. Quantification of gold labeling was done in 401 and 169 synapses in two animals each for GIPC and PSD-95, respectively.

Imaging and data analysis. All images were acquired with a $63 \times$ objective on a Zeiss (Oberkochen, Germany) LSM510 laser-scanning confocal microscope with $2 \times$ OPTICAL zoom. A series of optical sections was collected at intervals of $0.39 \mu \mathrm{m}$ to cover the entire dendrite. Pictures were acquired at $1024 \times 1024$ pixel resolution, and the resulting image was an average of four scans at the same focal plane. The same confocal acquisition setting was applied to all samples from the same experiment. The image data were analyzed and quantified using MetaMorph software (Universal Imaging, West Chester, PA). Intensity and density of puncta (with fluorescence at least two times background) are presented as the average fluorescence and the number of puncta in arbitrary units $(20 \mu \mathrm{m}$ of dendrite length). For colocalization analysis, the value is given in percentage colocalization, defined as the number of surface NR2B puncta overlapping completely or partially with myc-GIPC or PSD-95 puncta, divided by the total number of surface NR2B puncta in a $20 \mu \mathrm{m}$ dendrite segment. For bassoon, colocalization also includes adjacent puncta. For quantifying internalization, the intensities and numbers of the blue puncta (far red; internalized) and red puncta (rhodamine; remaining on the surface) were counted in a $20 \mu \mathrm{m}$ dendrite segment. The ratio of internalized/surface was calculated. For statistical analysis, images from at least two independent experiments were collected. The number of neurons for each count is specified in the figure legend. For each neuron, measurements were performed on five dendrite segments of $20 \mu \mathrm{m}$ in length; these were first grouped and averaged per neuron. Means from different neurons were averaged to obtain a final mean \pm SEM. Statistical significance between two data sets was calculated using a Student's $t$ test.

Functional analysis. Hippocampal pyramidal neurons were prepared from $18 \mathrm{~d}$ embryonic Sprague Dawley rats and grown in Neurobasal medium. Transfections of hippocampal neurons were done at 10 DIV, and whole-cell recordings were conducted at 13-14 DIV. Cerebellar granule cells (CGCs) from P7 rats were cultured and analyzed as described previously (Prybylowski et al., 2002, 2005). Transfections of CGCs were done at $5 \mathrm{DIV}$, and recordings were done 2-3 d after transfection. For both hippocampal and CGCs, whole-cell recordings were performed with the application of $200 \mu \mathrm{M}$ NMDA and $20 \mu \mathrm{M}$ D-serine with $1 \mu \mathrm{M}$ TTX in an $\mathrm{Mg}^{2+}$-free solution via a Y-tubing system. For CGCs, NMDA-miniature EPSCs (mEPSCs) were recorded in an $\mathrm{Mg}^{2+}$. free extracellular solution with $50 \mu \mathrm{m}$ bicuculline [or bicuculline methiodide (BMI)], $1 \mu \mathrm{M}$ TTX, and $10 \mu \mathrm{M}$ NBQX.

\section{Results}

\section{GIPC interacts with NR2 subunits}

We performed a yeast two-hybrid screen using the distal portion of the NR2B subunit (Fig. $1 A$ ) to identify proteins that interact with the cytoplasmic domains of the NMDA receptor and influence its trafficking. Two full-length clones encoding GIPC were among those identified as interacting with NR2B. To determine whether the association involved a PDZ domain, a series of mutations were made in GIPC (Fig. $1 B$ ) as well as in the PDZ binding domain (PDZ BD) of NR2B, and the yeast two-hybrid assay was used to determine interactions. These results show that the PDZ domain of GIPC interacts with NR2B, whereas the proline-rich and ACP (acyl carrier protein) domains of GIPC do not (Fig. 1C). Deletion of the terminal 7 amino acids of NR2B, which eliminates the PDZ BD, also blocked all interactions with GIPC as well as with PSD-95, which served as a control. Previous studies have shown that PDZ interactions with GIPC can be eliminated by mutation in the PDZ domain (Lou et al., 2001). Mutation of residues 143-145 (LGL $>$ AAA) of GIPC eliminated its interaction with NR2B. This mutation may result in a dominantnegative construct (GIPC-DN) and was used later in functional studies of neurons. GIPC has been shown to accept a wider range of binding partners and interacts with C-terminal motifs of all three classes of PDZ BDs (Reed et al., 2005). Proteins with alanine as the distal amino acid interact with GIPC (Bunn et al., 1999), whereas they do not interact with most type $1 \mathrm{PDZ}$ proteins. Mutating V1482A of NR2B retained the interaction with GIPC but not with PSD-95 (Fig. 1C), thus illustrating an important difference between GIPC and the PSD-95 family of MAGUKs. GIPC also interacted with NR2A in the yeast two-hybrid assay (our unpublished data). Unlike NR2B, NR2A-containing receptors do not require a PDZ interaction for synapse localization (Barria and Malinow, 2002; Prybylowski et al., 2005; Thomas et al., 2006), suggesting that PDZ interactions have different functions for these two subunits. 
The interaction between GIPC and NR2 was investigated in heterologous cells and in mammalian brain. The TacNR2B chimera (consisting of a single transmembrane domain protein, Tac, and the distal portion of NR2B) and GIPC colocalized after transfection in COS cells (Fig. 1D). Deletion of the PDZ BD of NR2B eliminated the colocalization, whereas the V1482A mutant colocalized like the wild type (WT). A similar colocalization was seen after cotransfection of GIPC with full-length NR2B and NR1 in COS cells (supplemental Fig. $1 A, B$, available at www.jneurosci.org as supplemental material) as well as with TacNR2A (supplemental Fig. $1 C$, available at www.jneurosci.org as supplemental material). Transfection with the AMPA receptor subunit, GluR1 (tagged with HA), and GIPC showed no colocalization (supplemental Fig. $1 D$, available at www.jneurosci.org as supplemental material). To verify that a GIPC/NMDA receptor interaction occurs in brain, we showed that immunoprecipitation of detergent solubilized GIPC coimmunoprecipitates NR2B and NR1 (Fig. 1E). Attempts to show coimmunoprecipitation of GIPC after immunoprecipitation with antibodies to NMDA receptor subunits were not successful. Failure to demonstrate coimmunoprecipitation in both directions is common in the literature; for example, antibodies to the NMDA receptor coimmunoprecipitate PACSIN1, whereas antibodies to PACSIN1 do not coimmunoprecipitate NMDA receptor subunits (Perez-Otano et al., 2006). This is commonly attributed to inaccessibility of the epitope of one of the partners but may also be attributable to large differences in the total amount of the partners.

GIPC clusters TacNR2 chimeras on the surface of COS cells and is associated with internalized TacNR2

TacNR2 constructs are expressed on the surface of heterologous cells and are internalized like the full-length subunit (Roche et al., 2001). Coexpression of GIPC led to a clustering of TacNR2A and TacNR2B on the cell surface and a colocalization of surface TacNR2A and TacNR2B with GIPC (Fig. $2 A, B$, and supplemental Fig. $1 C$, available at www.jneurosci.org as supplemental material). These results show that GIPC is associated with TacNR2A and TacNR2B on the cell surface, which is consistent with several other reports showing that GIPC is associated with surface proteins. GIPC also has been shown to be associated with internalized proteins. This could result from either retaining an association formed on the cell surface or establishing an association after internalization. To determine whether GIPC is associated with internalized TacNR2B, live cells were surface labeled with anti-Tac antibodies,

\section{B}

\section{NR2B C-terminus}

1315-ALAPRSVSLKDKGRFMDGSPYAHMFEMPAGESSFANKSSVPTAGHHHHNNPGSGYMLSKSLYPDRVTQN OFIPTFGDDQCLLHGSKSYFFRQPTVAGASKTRPDFRALVTNKPVVVTLHGAVPGRFQKDICIGNQSNPCVPNNK NPRAFNGSSNGHVYEKLSSI ESDV-1482
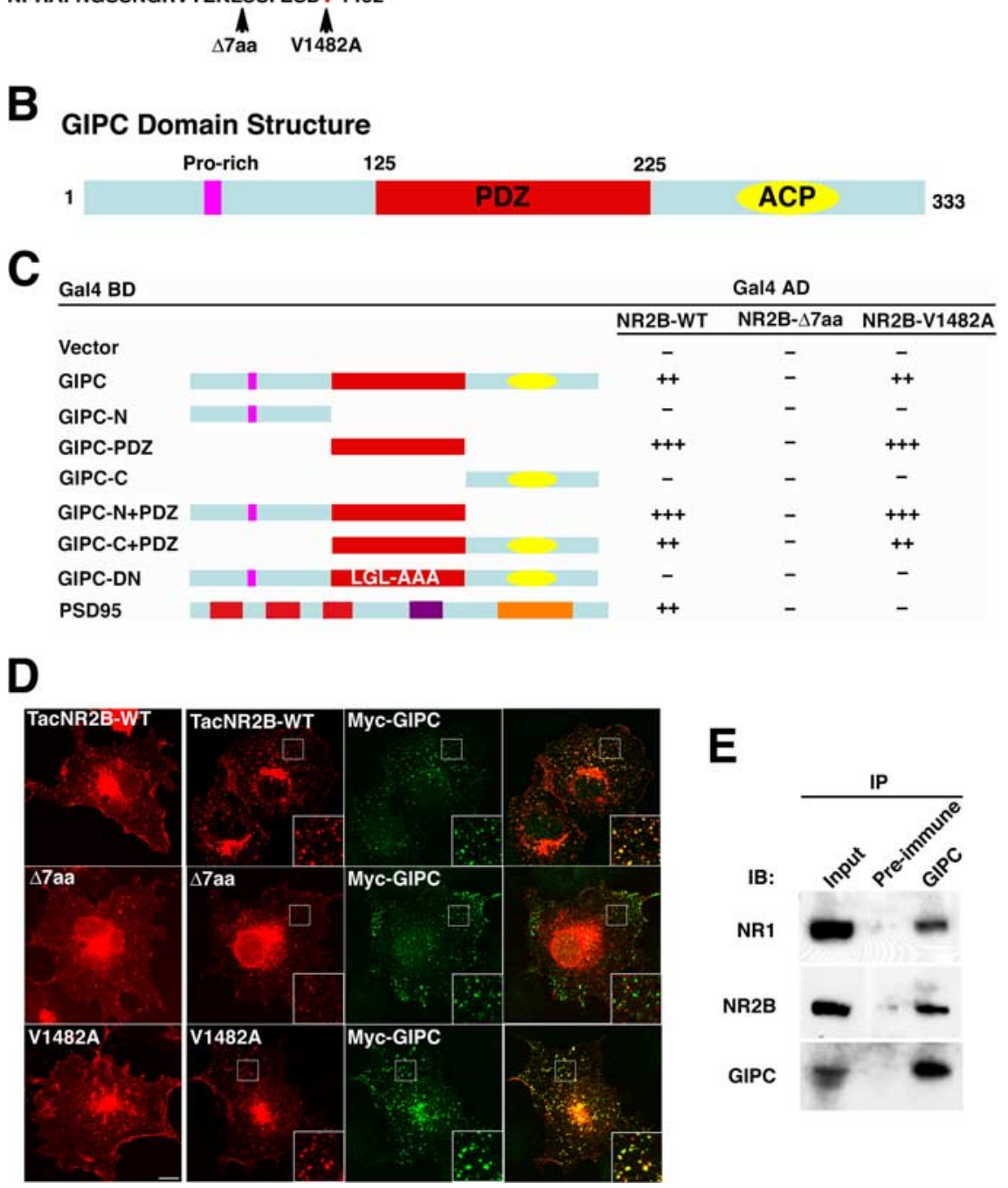

Figure 1. GIPC interacts with NMDA receptors. $A$, The sequence of the distal C terminus of NR2B (1315-1482) that was used in the yeast two-hybrid screen. The sites of the NR2B- $\Delta 7$ aa truncation and the NR2B-V1482A mutation are indicated by arrows. $B$, 125-225), and an ACP motif. $C$, Interactions between GIPC and the C terminus of NR2B subunits were tested in yeast by induction of the reporter gene LACZ ( $\beta$-galactosidase) and HIS3. Binding to NR2B is mediated by the PDZ motif of GIPC. The PDZ-binding motif at the extreme $C$ terminus of NR2B is required for interaction with GIPC. The interaction is maintained if the last amino acid, $V$, is substituted with $A$; this substitution eliminates the interaction with PSD-95. D, The interaction between GIPC and NR2B was also demonstrated by their colocalization in COS cells. Total immunostaining of COS cells after transfection of TacNR2B-WT, TacNR2B- $\Delta 7$, or TacNR2B-V1482A alone (left panel) or with GIPC (right three panels) is shown. Scale bar, $10 \mu \mathrm{m}$; insets, $4 \mu \mathrm{m}$. E, Coimmunoprecipitation of NR1 and NR2B subunits with GIPC from adult rat hippocampus after DOC solubilization; immunoprecipitation (IP) with antibodies to GIPC coimmunoprecipitates NR1 and NR2B. IB, Immunoblot.

and the antibody-TacNR2B complex was allowed to internalize for $30 \mathrm{~min}$ (Fig. 2C,D). GIPC and TacNR2B colocalized, and this colocalization was mostly dependent on the PDZ interaction, whereas the V1482A mutation of TacNR2B did not decrease colocalization.

To determine whether GIPC is associated with a specific population of endosomes, we studied the colocalization of GIPC with EEA1 and Rab5, markers for early endosomes, and Rab11, a marker for recycling endosomes. COS cells transfected with GIPC showed little colocalization with native EEA1, or with transfected Rab 5 or Rab11 (supplemental Fig. 2A, available at 


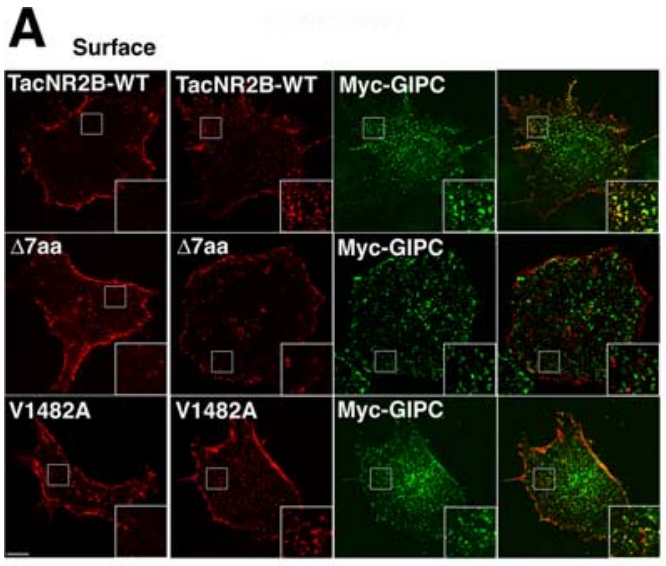

B

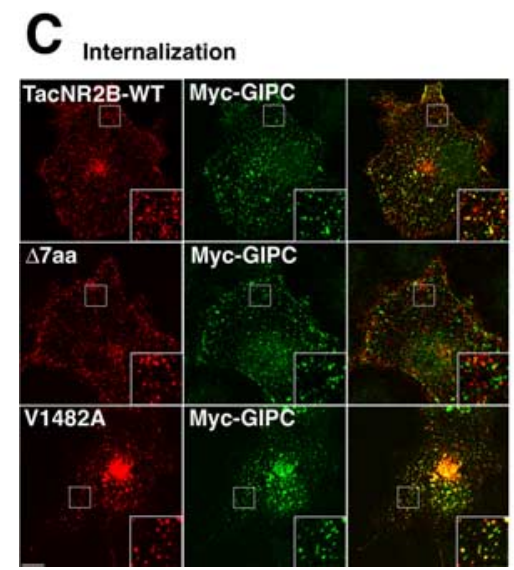

Figure 2. GIPC is associated with TacNR2B on the cell surface and after internalization. $A, B, C O S$ cells were transiently transfected with TacNR2B constructs alone (left panels) or cotransfected with myc-GIPC (right three panels). Surface labeling was determined by incubating cells with anti-Tac antibodies for $1 \mathrm{~h}$ on ice. Overexpression of myc-GIPC clusters surface TacNR2B-WT and TacNR2B-V1482A but not TacNR2B- $\Delta 7$. Surface WT and V1482A TaCNR2B are colocalized with GIPC as seen in the right panel, but mutation of the PDZBD disrupts this colocalization. Data in $B$ represent mean \pm SEM of the percentage of surface TacNR2B (or mutant construct) puncta that colocalized with myc-GIPC puncta ( $n=10$ cells from 2 experiments; ${ }^{*} p<0.001$ for NR2B $\Delta 7$ compared with TacNR2B-WT). C, $D$, COS cells were transiently transfected with TacNR2B and myc-GIPC. After incubating with anti-Tac antibodies for $1 \mathrm{~h}$ on ice, cells were returned to $37^{\circ} \mathrm{C}$ for internalization for $30 \mathrm{~min}$. Immunostaining of internalized constructs shows that myc-GIPC is associated with internalized TacNR2B and TacNR2B-V1482A but not TacNR2B- $\Delta$ 7. Data in Drepresent mean \pm SEM of the percentage of internalized TacNR2B (ormutant construct) puncta that colocalized with myc-GIPC puncta ( $n=6$ cells from 2 experiments; ${ }^{*} p<0.001$ for NR2B $\Delta 7$ compared with TacNR2B-WT). Scale bars: $A, C, 10 \mu \mathrm{m}$; insets, $4 \mu \mathrm{m}$.

www.jneurosci.org as supplemental material). However, triple transfection of GIPC with Rab5 or Rab11 and TacNR2B showed a colocalization of the three proteins after internalization of surface-labeled TacNR2B (supplemental Fig. $2 B$, available at www. jneurosci.org as supplemental material). These results suggest that TacNR2B recruits GIPC to both early and recycling endosomes. GIPC has been reported to associate with newly internalized membrane vesicles immediately after the removal of the clathrin coat (Aschenbrenner et al., 2003; Hasson, 2003). Our experiments suggested that GIPC remains associated with TacNR2B because it is trafficked through both early and recycling endosomes.

To investigate more completely the time course of this association, we performed a pulse-label experiment in which surface TacNR2B was labeled with anti-Tac antibodies and the complex was allowed to internalize for $5 \mathrm{~min}$ and analyzed either immediately or 25 min later (supplemental Fig. 3, available at www.jneurosci.org as supplemental material). The remaining surface-associated antibodies were removed by acid treatment. Quantification of colocalization showed that $\sim 20 \%$ of the internalized TacNR2B is colocalized with GIPC at both 5 and $30 \mathrm{~min}$ after the beginning of internalization.
These results are consistent with our findings showing that GIPC associates with TacNR2B at both early and recycling endosomes and show that GIPC stays associated with TacNB2B for a relatively long time after internalization. Together, our results suggest that GIPC associates with surface TacNR2B and remains associated for at least $30 \mathrm{~min}$ after internalization as it traffics through early and recycling endosomes. However, these results do not rule out an alternative interpretation in which the association of GIPC with surface TacNR2B is broken before internalization and a new association is formed immediately after internalization.

\section{GIPC does not affect total dendritic NMDA receptors in hippocampal neurons}

To study further the interaction between GIPC and the NMDA receptor and to determine whether GIPC plays a role in NMDA receptor trafficking, we used the dominant-negative (LGL $>$ AAA mutation) construct of GIPC (GIPC-DN), which is incapable of forming PDZ interactions, and siRNA to decrease expression of GIPC in cultured hippocampal neurons. Because GIPC is ubiquitously distributed and has multiple functions, including association with some proteins early in their biosynthesis, we first asked whether GIPC regulated total NMDA receptor levels in dendrites. We analyzed both transfected myc-NR2B (supplemental Fig. $4 A, B$, available at www.jneurosci. org as supplemental material) and endogenous NR1 (supplemental Fig. 5, available at www.jneurosci.org as supplemental material) after overexpression of GIPC or expression of GIPC-DN. Cells were permeabilized with detergent to allow staining of both surface and intracellular receptors. In both cases, total dendritic staining levels were unchanged. Two different constructs of siRNA were used. Although both were able to reduce expression of transfected rat GIPC in COS cells (supplemental Fig. 4C, available at www.jneurosci.org as supplemental material), siRNA-2 proved to be more effective and was used in subsequent studies. Both siRNAs reduced endogenous GIPC in cultured neurons, while having no effect on SAP102, a PDZ protein that served as a control (supplemental Fig. $4 C, D$, available at www.jneurosci.org as supplemental material). Like overexpression of GIPC and expression of GIPC-DN, GIPC-siRNA did not alter the levels of total endogenous NR1 (supplemental Fig. 5, available at www.jneurosci.org as supplemental material) or transfected myc-NR2B (supplemental Fig. 4E, F, available at www.jneurosci.org as supplemental material) in neurons. These results show that GIPC overexpression, GIPC-DN, and GIPC downregulation with siRNA do not affect the total levels of NMDA receptors in dendrites.

\section{GIPC regulates surface expression of NMDA receptors in hippocampal neurons}

Controlling the number of receptors on the cell surface is a critical mechanism in regulating the function of glutamate receptors. 
Although changes in surface expression of NMDA receptors are thought to be less fluid than those of AMPA receptors, several studies have now shown that the number of surface NMDA receptors can be altered under various experimental conditions. To investigate whether GIPC plays a role in regulating the surface expression of NMDA receptors, NR2A and NR2B with a flag or myc epitope tag on their extracellular $\mathrm{N}$ termini were transfected along with GIPC constructs, and surface expression was monitored by labeling live neurons with anti-flag and antimyc antibodies, following a widely used standard labeling protocol. Both flag- and myc-tagged constructs gave similar results and were used interchangeably depending on compatibility with antibodies to other proteins that were colabeled. GIPC overexpression increased both the density of surface NR2B puncta as well as the intensity of NR2B, whereas GIPC-DN transfection decreased both density and intensity (Fig. $3 A, C, D$ ). As a control to verify that our protocol did not lead to labeling of internal proteins, we show that neurons transfected with myc-GIPC, a cytoplasmic protein, were unlabeled with the anti-myc antibody applied to live neurons (Fig. 3B). Downregulation of GIPC with siRNA similarly decreased the surface expression of NR2B (Fig. 3E-G). These results show that GIPC plays a role in regulating the number of NR2B-containing NMDA receptors on the cell surface of cultured neurons.

We also transfected neurons with NR2A that was epitope tagged at its $\mathrm{N}$ terminus to determine whether GIPC affected the surface expression of NR2A (Fig. 4). Like NR2B, NR2A surface expression was significantly decreased with either GIPC-DN or siRNA. Interestingly, however, overexpression of GIPC did not increase surface NR2A, indicating a difference in the role of GIPC in the trafficking of NR2A- and NR2Bcontaining receptors. GIPC expression did not affect the surface expression of GluR1 (supplemental Fig. 6, available at www.jneurosci.org as supplemental material).

\section{Effects of GIPC expression on native NMDA receptors}

Our results on NMDA receptor surface expression were obtained using epitope-tagged NR2A and NR2B, raising the possibility that the findings applied only to overexpressed receptors. To address this, we measured the effect of GIPC overexpression and knock-down with siRNA on whole-cell currents of cultured hippocampal neurons. Our results showed a slight, but not statistically significant, increase in current density with GIPC overexpression and a significant decrease in current density with siRNA (Fig. 5A,B). The slight increase in current density with GIPC overexpression supports our immunocytochemistry data showing an increase in surface expression of NR2B but no increase in NR2A with GIPC overexpression. Hippocampal neurons at this age express both NR2A and NR2B (Sans et al., 2000). The magnitude of decrease with siRNA (37\%) is similar to the reductions we measured immunocytochemically for NR2B (46\%) and NR2A (34\%). We also measured the effects of GIPC expression on current density on cultured CGCs. Results on whole-cell current density with changes in GIPC expression were similar to those obtained with hippocampal neurons (Fig. 5C). However, a statistically significant increase (59\%) in whole-cell current was seen with overexpression of GIPC. siRNA caused a modest (15\%), but statistically insignificant, decrease in whole-cell current; analysis of the results for individual cells shows a range of effect of siRNA as well as for GIPC overexpression (Fig. 5C) with a greater number of cells with lower current density with siRNA and higher current density with GIPC overexpression. This finding is consistent with there being heterogeneity in the granule cell population, which may reflect slightly different stages of synaptic development. Therefore, the effect of GIPC expression on wholecell currents in hippocampal and CGCs illustrates some differences between these two cell types, although the general trends are the same and consistent with our immunocytochemical results on the hippocampal neurons.

We also determined the effects of GIPC expression on synaptic NMDA receptors. This was done on cultured CGCs, which allows quantitation of mEPSCs (Prybylowski et al., 2002). Changes in GIPC expression had no significant effect on current amplitudes (Fig. 5D,E). We have shown previously that overex- 

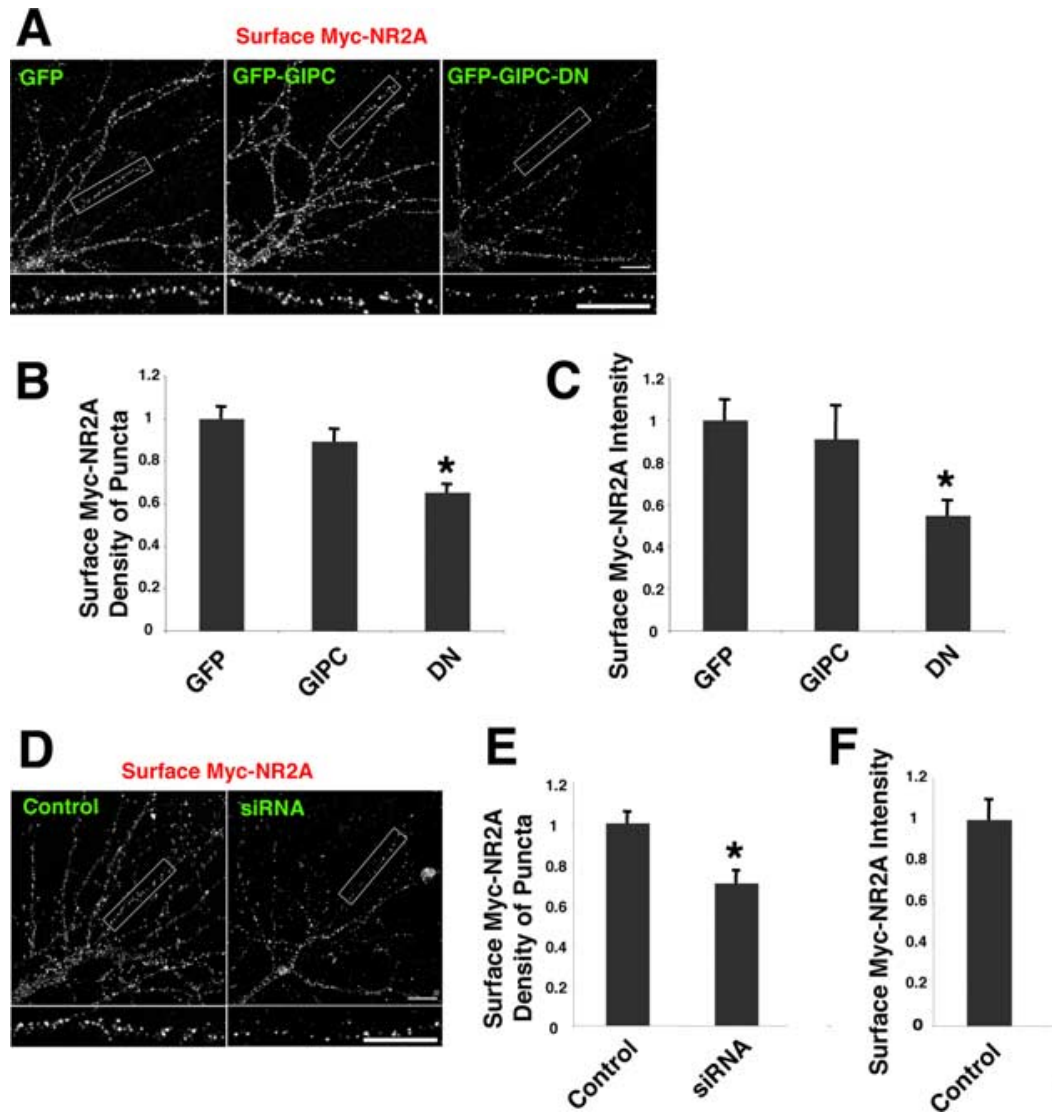

Figure 4. GIPC expression changes surface NR2A. $A-C$, Total surface immunostaining of myc-NR2A in hippocampus neurons when cotransfected with GFP, GFP-GIPC, or GFP-GIPC-DN. Quantification of the density and intensity of surface puncta for mycNR2A in neurons shows that GIPC-DN decreases surface labeling. Data represent mean \pm SEM of density of surface puncta and their intensity normalized to values obtained with GFP ( $n=14$ neurons from 3 experiments; ${ }^{*} p<0.05$ compared with GFP). $D-F$, siRNA knock-down of GIPC expression reduces surface expression of myc-NR2A. Total surface immunostaining of myc-NR2A in hippocampus neurons transfected with control or GIPC-siRNA-2 is shown. Quantification shows decreases in the density and intensity of surface puncta with siRNA. Data represent mean \pm SEM of density or intensity of puncta in dendrites normalized to values obtained for control ( $n=14$ neurons from 3 experiments; ${ }^{*} p<0.05$ ). Hippocampus neurons 13 DIV were used. Scale bars: $A, D, 10 \mu \mathrm{m}$.

pression of NR2B causes a decrease in deactivation kinetics reflecting an increased proportion of NR2B-containing receptors in the synapse (Prybylowski et al., 2002), which was confirmed by an increase in the ability of an NR2B-selective antagonist to block NMDA-mEPSCs (Prybylowski et al., 2002). Mutation of the PDZ $\mathrm{BD}$ blocks the addition of NR2B-containing receptors. As we showed above, mutation of the terminal amino acid (V1482A) of NR2B disrupts the interaction of NR2B with PSD-95 but not with GIPC. We expressed NR2B V1482A in cultured CGCs and investigated the properties of synaptic NMDA receptors by analyzing NMDA-mEPSCs in transfected CGCs. NMDA-mEPSCs were recorded in the presence of TTX, NBQX, and bicuculline with a solution lacking $\mathrm{Mg}^{2+}$ as described in detail previously (Prybylowski et al., 2002, 2005). NR2B V1482A gave results (Fig. 5F) indistinguishable from those of control cells expressing GFP and $\mathrm{NR} 2 \mathrm{~B} \Delta 7$, which has its entire PDZ BD deleted. In contrast, expression of NR2B, consistent with what we reported previously (Prybylowski et al., 2002), caused a slowing of the deactivation kinetics of the NMDA-mEPSC because of the slow kinetics of NMDA receptors containing the NR2B subunit. This indicates that NR2B-containing receptors entered the synapse. Together, our results indicate that NR2B V1482A, like NR2B $\Delta 7$, is excluded from the synapse, suggesting that GIPC is not playing a direct role

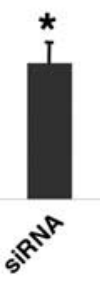

in the retention of NR2B-containing receptors at the synapse. Although overexpression of GIPC had no effect on the deactivation kinetics, siRNA had a significant effect on the kinetics (19\% reduction in $\tau_{\mathrm{w}}$ ), suggesting a possible role in influencing the relative amounts of NR2Aand NR2B-containing receptors at the synapse.

GIPC is associated with a subpopulation of surface receptors and stabilizes NMDA receptors on the cell surface of neurons

Our results in COS cells showed that GIPC is associated with surface TacNR2A and TacNR2B. To determine whether GIPC is associated with surface NMDA receptors in neurons, we studied the colocalization of surface NR2B and GIPC. As shown in Figure 6 , we found that $26 \%$ of the surface NR2B puncta are colocalized with GIPC. This was dependent on the PDZ interaction because colocalization of GIPC and the NR2B mutant lacking the PDZ BD was substantially reduced, whereas colocalization of the V1482A mutant, which retains its interaction with GIPC, was similar to that of the WT. The fact that the V1482A mutant behaved like the WT supports the interpretation that the GIPC/NMDA receptor link is direct rather than through another PDZ protein such as PSD-95, which does not tolerate the V1482A mutation. The fraction of surface NR2B receptors colocalized with GIPC is much less than that colocalized with PSD-95 (58\%), a synaptic marker. Therefore, GIPCassociated receptors may be a subset of synaptic receptors or represent another population of receptors.

The association of GIPC with a population of surface NMDA receptors raises the possibility that the effects of GIPC overexpression or disruption of expression on surface receptors could be linked to this association. An interaction with PSD-95 has been shown previously to stabilize NMDA receptors on the cell surface (Roche et al., 2001), and GIPC may have a similar function for a subset of NMDA receptors; a decrease in GIPC would then be accompanied by a decrease in surface NMDA receptors. To address this, we asked whether GIPC expression affected internalization of surface NR2B-containing receptors on cultured neurons using a well characterized antibody feeding protocol in which live neurons were exposed to antibodies to myc or flag and the antibody-receptor complex was allowed to internalize. Several studies have shown that NMDA receptors are internalized in cultured neurons and that clathrin-dependent endocytosis may be a major mechanism mediating this process (Roche et al., 2001; Lavezzari et al., 2004; Scott et al., 2004; Montgomery et al., 2005; Prybylowski et al., 2005; Perez-Otano et al., 2006). As shown in Figure $7 A, B$, coexpression with GIPC-DN dramatically increased the internalization of surface-labeled NR2B, whereas GIPC overexpression may have produced a slight, but statistically insignificant, decrease in internalization. Like GIPC-DN, use of 
siRNA to decrease expression of GIPC also dramatically increased internalization of surface-labeled NR2B (Fig. 7C,D). These results suggest that GIPC plays a role in regulating NR2B on the cell surface, which could involve altering endocytosis, exocytosis, or the stability of the surface receptor.

To analyze our data shown in Figure $7 A-D$, results were expressed as the internalization index, which is the ratio of internalized puncta (intensity) to those remaining on the surface, following published methods (Perez-Otano et al., 2006). Thus, internalization is measured relative to the amount on the surface. But as we illustrated above, GIPC-DN and GIPC-siRNA decrease the amount of surface NMDA receptor. If the intensity of the internalized receptors are analyzed, and not expressed as a ratio of the surface label, we find that the same amount of receptor is internalized for GFP, GIPC, and GIPC-DN (Fig. 7E). Therefore, the rate of internalization is not affected by GIPC overexpression or GIPC-DN, but rather, a smaller number of receptors are stable on the cell surface. These findings are consistent with the interpretation that GIPC is stabilizing NMDA receptors on the cell surface rather than affecting their endocytosis or exocytosis.

\section{GIPC is not enriched at the synapse}

Our results show that GIPC is associated with a pool of surface NMDA receptors and that it plays a role in controlling the internalization of the receptors. Although the majority of surface NMDA receptors are found at the synapse, there is a significant pool of extrasynaptic receptors, which may be enriched in NR2B (Rumbaugh and Vicini, 1999; Tovar and Westbrook, 1999). We performed several analyses to determine whether GIPC is associated with a specific pool of surface NMDA receptors. These studies were done primarily with a selective antibody to GIPC that we developed (supplemental Fig. 7, available at www.jneurosci.org as supplemental material). We first asked whether GIPC was enriched at the synapse by determining whether it is colocalized in hippocampal cultures with bassoon and PSD-95 presynaptic and postsynaptic markers, respectively. Our results showed that $<10 \%$ of the GIPC was colocalized with these synaptic markers (Fig. $8 A, B$ ). We performed a biochemical subfractionation to determine whether GIPC is enriched in the PSD fraction. GIPC was decreased in these fractions, whereas PSD-95, known to be abundant at the PSD, was highly enriched (Fig. 8C). GIPC, however, was relatively abundant in the synaptic membrane fraction, which contains both presynaptic and postsynaptic membranes
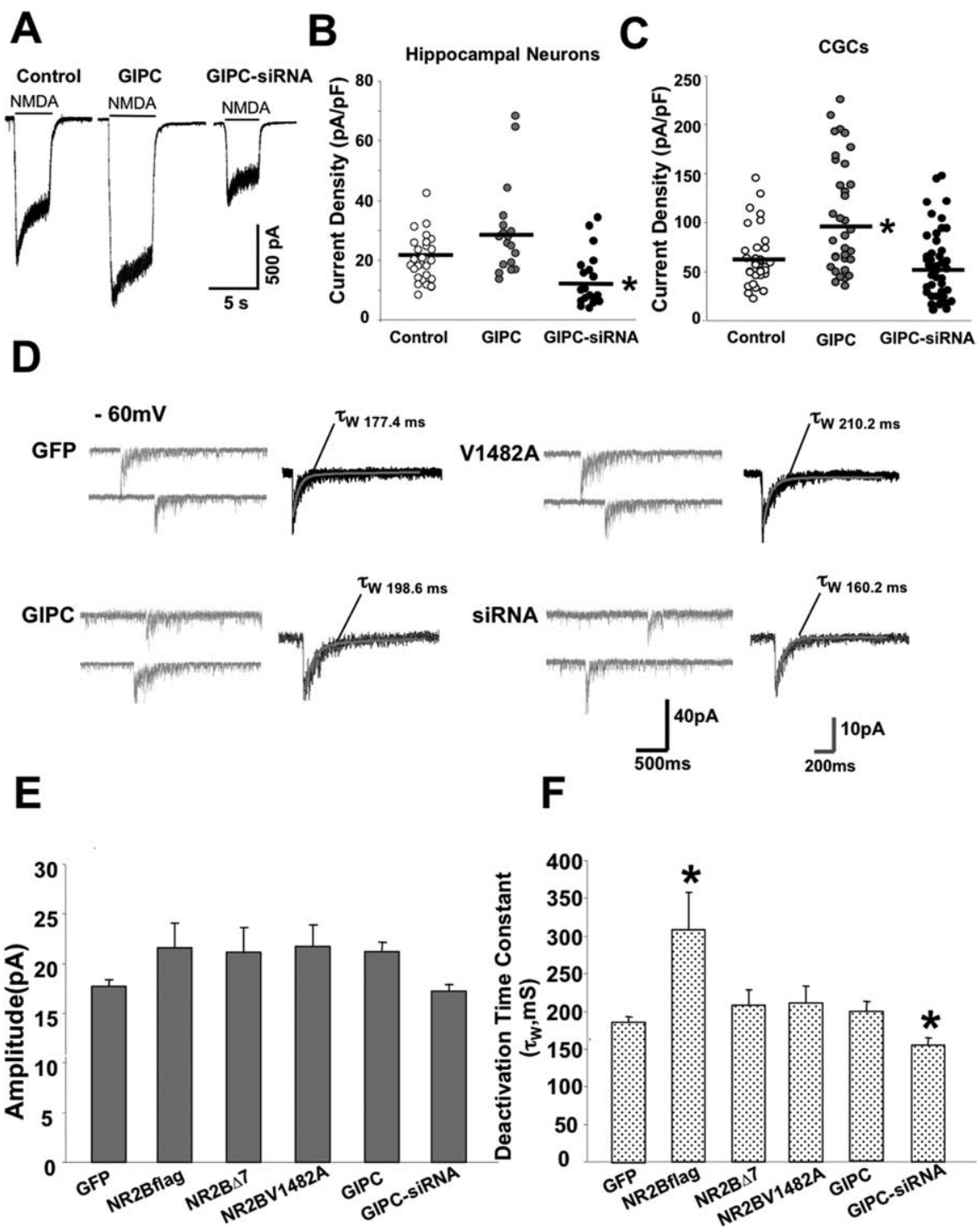

Figure 5. GIPC expression changes endogenous NMDA receptors. $\boldsymbol{A}$, Example traces showing whole-current responses from individual cultured hippocampal neurons. Hippocampal neurons were transfected with GFP, GIPC, or GIPC-siRNA at 10 DIV, and the whole-cell current responses to $200 \mu \mathrm{M}$ NMDA (in $\mathrm{Mg}^{2+}$ free solution) were measured at 13-14 DIV. B, Summary of current density responses from cultured hippocampal neurons transfected with GIPC constructs as indicated. The current density measurement $(\mathrm{pA} / \mathrm{pF}$ ) was used to compensate for neuron to neuron variability in current responses by normalizing current peak amplitude (pA) to membrane capacitance (pF). Neurons expressing GIPC-siRNA show significantly reduced current density responses compared with the control group. C, Summary of current density response from cultured CGCs transfected with GIPC constructs as indicated. Transfection of GIPC significantly increases current density responses compared with the control GFPexpressing cells. $\boldsymbol{D}$, Representative traces of NMDA-mEPSC recordings from CGCs transfected with GFP or cells transfected with GIPC, GIPC-siRNA, or NR2B V1482A as indicated. TTX, NBQX, and bicuculline or BMI were present in $\mathrm{Mg}^{2+}$-free solution to pharmacologically isolate NMDA-mEPSCS. $E$, Summary of averaged peak amplitude of NMDA-mEPSCs illustrating that expression of different NR2B constructs, GIPC, or GIPC-siRNA produces no significant change compared with control GFP-transfected GGCs. $\boldsymbol{F}$, Average of weighted time constant of decay $\left(\tau_{\mathrm{w}}\right)$ of NMDA-mEPSCs. Expression of NR2Bflag causes a significant slowing of the deactivation kinetics of NMDA-mEPSCs, as we have previously shown (Prybylowski et al., 2002), but transfection of GIPC-siRNA significantly increases the deactivation rate. No significant changes are observed from neurons expressing other NR2B constructs and GIPC. Data are shown as mean \pm SEM; ANOVA, ${ }^{*} p<0.01$ versus control. Averaged data from cells in different groups (at least 15 cells per group) are shown.

and would include both synaptic and extrasynaptic receptors, and the intracellular membrane fraction. We then used postembedding immunogold labeling to determine the distribution of GIPC in excitatory spine synapses of the adult rat hippocampus (P35). These results confirmed the low amounts of GIPC found at the spine synapse and showed that GIPC is significantly more abundant at the extrasynaptic membrane and most abundant in 
A

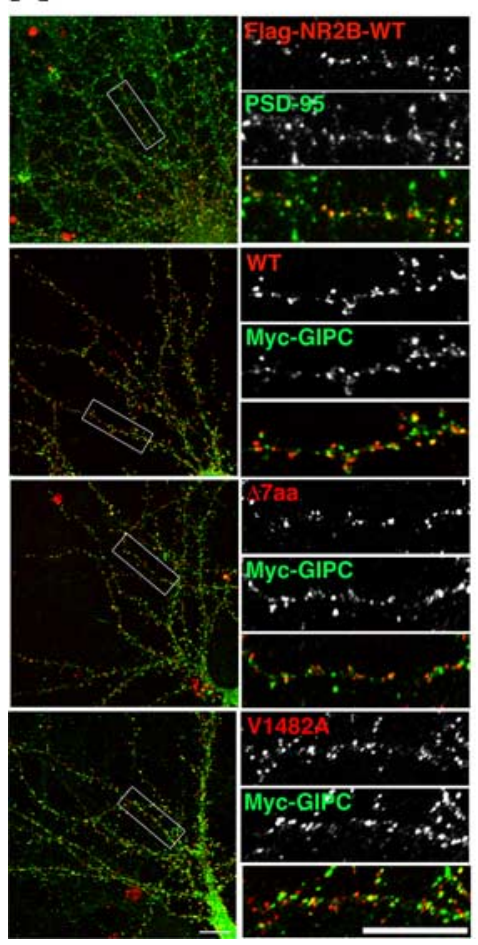

B

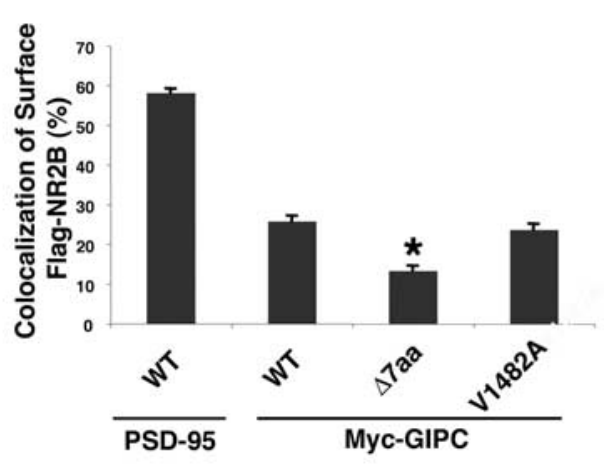

receptors on the surface of neurons. Regulating the number of receptors on the cell surface is a major mechanism for controlling glutamate receptor function at the synapse. Studies of mechanisms controlling receptor numbers have focused mainly on synaptic receptors, and most models include clustering of receptors at the postsynaptic membrane through attachments to the PSD complex via the PSD-95 family of MAGUKs. Our results show that another PDZ protein, GIPC, may play an important role in determining the number of NMDA receptors on the cell surface.

\section{GIPC has multiple functions}

GIPC is a ubiquitous protein (De Vries et al., 1998), and a growing number of proteins has been shown to interact with GIPC with a range of functional implications, including organizing and regulating signaling cascades (Lou et al., 2001), anchoring proteins at specific subcellular compartments (Wang et al., 1999) and the plasma membrane (Blobe et al., 2001; Awan et al., 2002; Hirakawa et al., 2003; Jeanneteau et al., 2004b), and trafficking of intracellular organelles (Aschenbrenner et al., 2003; Hirakawa et al., 2003; Dance et al., 2004; Reed et al., 2005; Lin et al., 2006; Naccache et al., 2006; Varsano et al., 2006). GIPC associations frequently occur at endosomes but also occur earlier in biosyn-

the cytoplasm (Fig. 8D,E). In contrast, almost all gold labeling for PSD-95 was found at the synapse (with some in the cytoplasm adjacent to the PSD). In the extrasynaptic membrane areas of excitatory spine synapses, labeling for GIPC was seen both at the edge of the synapse active zone and also further away, on the sides of the spine heads (supplemental Fig. 8, available at www.jneurosci.org as supplemental material).

Based on the distribution of GIPC and its association with a relatively small pool of surface NMDA receptors, our results support the interpretation that GIPC associates preferentially with extrasynaptic NMDA receptors and helps to stabilize them on the cell surface. If this is the case, decreases in surface NR2B seen with transfection of GIPC-DN may reflect a preferential loss of extrasynaptic receptors. To address this, we determined whether the loss of surface NR2B with cotransfection of GIPC-DN changes the colocalization of surface NR2B with the synaptic marker, bassoon. Bassoon is a presynaptic protein and is preferred over PSD-95 because it is less likely to be subjected to any indirect effects that may occur in the transfected neuron. Our results show that expression of GIPC-DN led to a significant increase in the colocalization of surface NR2B and bassoon (Fig. $8 F, G$ ). Therefore, the remaining surface receptors have a preferred localization at the synapse consistent with a preferential loss of extrasynaptic receptors.

\section{Discussion}

In this study, we show that the PDZ protein, GIPC, interacts with a subpopulation of NMDA receptors on the cell surface of neurons and that changes in GIPC expression by overexpression, expression of GIPC-DN, or reduction by siRNA affect NMDA thesis (e.g., GIPC associates with the melanosomal membrane protein gp75 in the Golgi) (Liu et al., 2001). GIPC also is associated with uncoated endocytic vesicles shortly after losing their clathrin coats (Aschenbrenner et al., 2003; Hasson, 2003; Dance et al., 2004; Naccache et al., 2006).

\section{GIPC associates with NMDA receptors on the cell surface}

In COS cells, GIPC clusters and colocalizes with TacNR2A and TacNR2B chimeras in a PDZ-dependent manner. Immunofluorescence and EM data support a colocalization of GIPC with a subpopulation of surface NMDA receptors in neurons. Our results show that changes in GIPC expression significantly alter surface levels of NR2A and NR2B, as well as functional NMDA receptors determined by measuring whole-cell currents. Changes in cell-surface levels could result from changes in delivery to and removal from the cell surface, as well as changes in stability on the cell surface. By quantifying internalization of NR2B, we found that internalization (internalized/amount remaining on surface) was significantly increased with GIPC-DN and GIPC-siRNA, whereas GIPC overexpression slightly (but not significantly) decreased internalization. However, the actual amount of internalized receptor was the same for all three conditions. This suggests that the internalization process was unchanged, and because equilibrium between addition and removal must occur, the addition of receptor to the cell surface must also be unchanged. Therefore, GIPC likely plays a role in stabilizing NMDA receptors on the cell surface. We find that GIPC is not enriched at the synapse and that changes in GIPC expression do not affect the number of synaptic NMDA receptors. Furthermore, an NR2B 
construct with a PDZ BD that permitted interaction with GIPC but not with MAGUKs did not enter the synapse, as determined by deactivation kinetics showing that GIPC cannot support retention of NMDA receptors at synapses. Thus, GIPC may play a greater role in regulating the trafficking of extrasynaptic receptors than synaptic receptors.

GIPC forms dimers (Bunn et al., 1999; Gao et al., 2000; Blobe et al., 2001; Hirakawa et al., 2003; Jeanneteau et al., 2004a,b; Naccache et al., 2006) or higher multimers (Kedlaya et al., 2006), and might form large multimeric complexes involving several different proteins (Hirakawa et al., 2003; Naccache et al., 2006; Varsano et al., 2006). GIPC interacts with the actin-binding protein $\alpha$-actinin- 1 (Bunn et al., 1999) and could form a link with the actin cytoskeleton. Thus, a molecular scaffold could be formed at extrasynaptic sites and play roles in stabilizing NMDA receptors on the surface and in restricting receptors to specific areas of neurons. A GIPC-myosin VI complex could also help organize NMDA receptors through interactions with the actin cytoskeleton; however, myosin VI does not coimmunoprecipitate with NMDA receptors from brain, suggesting that if such interactions occur, they are either transient or minor (Osterweil et al., 2005).

GIPC could also function as an antagonist and prevent NMDA receptors from interacting with other PDZ proteins. Tip-1 plays such a role in its interaction with the potassium channel Kir 2.3 (Alewine et al., 2006). Like GIPC, Tip-1 is a small single PDZ domain protein that competes with mLin-7 and disrupts surface localization of Kir 2.3. In such a scenario, interaction of GIPC with the NMDA receptor would prevent the receptor from interacting with another PDZ protein, leading to internalization, or it could prevent interaction with a PDZ protein present at the PSD and prevent the receptor from entering the synapse. Such a mechanism might also be used to differentially regulate NR2A- and NR2Bcontaining receptors. The distribution of GIPC, which is widespread throughout the cytoplasm, making it available for associating with other proteins, is well suited to play a role as an antagonist.

\section{GIPC associates with intracellular NMDA receptors}

NMDA receptors are internalized through clathrin-mediated endocytosis, leading to either degradation or recycling (Roche et al., 2001; Scott et al., 2004; Montgomery et al., 2005). This process may occur rapidly (Prybylowski et al., 2005) and may be constitutive or activity related (Snyder et al., 2001). In transfected COS cells, we find that GIPC is associated with internalized TacNR2B at both early and recycling endosomes. Their colocalization is dependent on the PDZ interaction of TacNR2B, indicating that GIPC is recruited to endosome populations by TacNR2B. In neu-
B

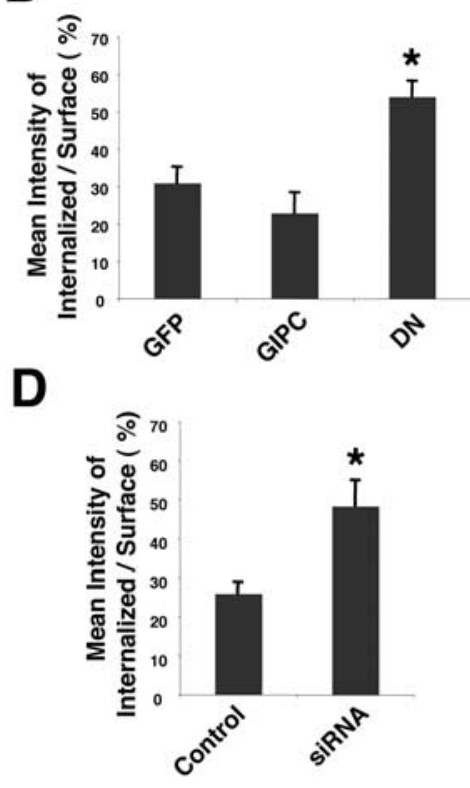

E

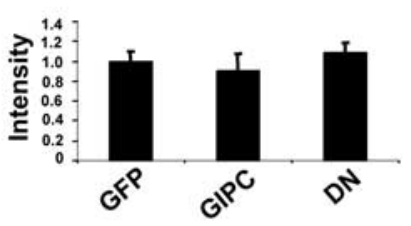

Figure 7. GIPC expression and regulation of the internalization of NR2B in hippocampal neurons. Hippocampal neurons coexpressing myc-NR2B and GIPC constructs were incubated for $45 \mathrm{~min}$ at room temperature with anti-myc antibodies and 作 , D, Immunostaining of surface and internalized myc-NR2B when coexpressed with control or GIPC-siRNA-2. Data represent ntensity of internalized immunostaining of myc-NR2B when coexpressed with GFP, GIPC, or GIPC-DN. Hippocampus neurons 13 DIV were used. Scale bars: $A, C, 10 \mu \mathrm{m}$.

rons, GIPC is most abundant in the dendritic cytoplasm, and our EM analyses of hippocampal tissue show that GIPC has a distribution complementary to that of PSD-95. Our biochemical subfractionation data also show that GIPC is not associated with the postsynaptic protein-scaffolding complex but is abundant in synaptic membrane and internal membrane fractions.

Our findings showing GIPC associated with both surface and cytoplasmic NMDA receptors are consistent with two different interpretations. First, GIPC associates with a population of surface receptors and remains associated as the receptor is internalized. In fact, GIPC binding may be required for internalization. Once internalized, GIPC may remain with the receptor as it passes through the recycling pathway; it may be removed before exocytosis, or it may stay associated as the receptor is delivered to the cell surface. Removal of GIPC may occur only when NMDA receptors become part of the synaptic complex. In the second scenario, GIPC is associated with surface receptors, but this association is disrupted before the receptor is internalized. Internalization may require loss of GIPC from the NMDA receptor com- 

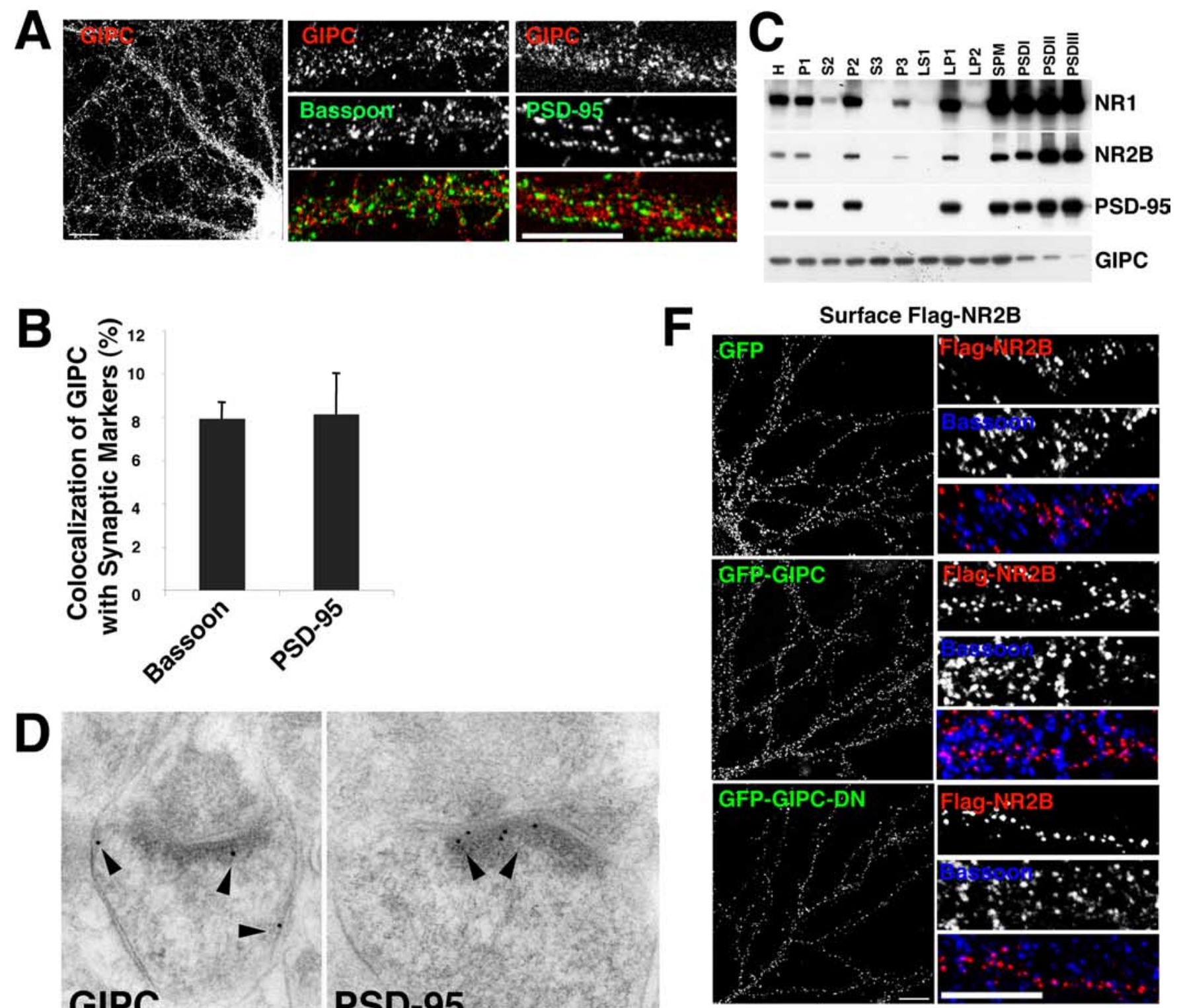

\section{GIPC}
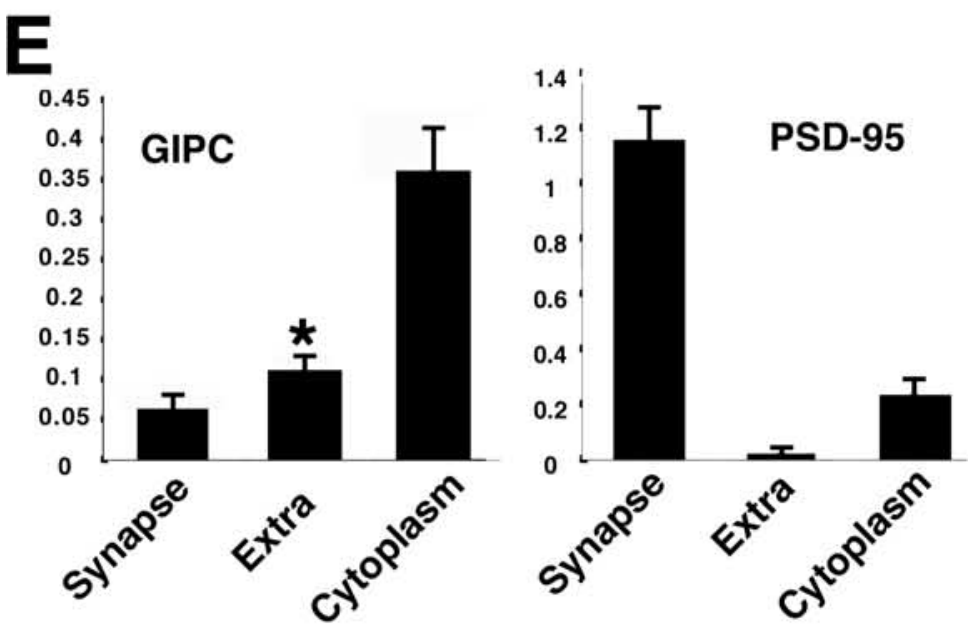

Figure-8

G

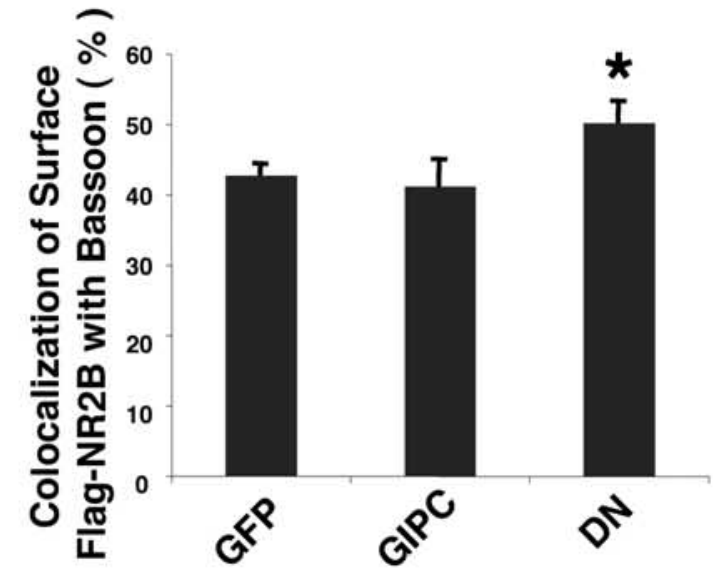

Figure 8. GIPC is not enriched at the synapse and prefers association with extrasynaptic NMDA receptors. $A, B$, Distribution of native GIPC (red) in hippocampal neurons double stained with bassoon (green) or PSD-95 (green) antibodies. Quantification shows limited colocalization $(<10 \%)$ of puncta of GIPC with bassoon or PSD-95. Data represent mean \pm SEM of percentage of native GIPC puncta colocalized with bassoon or PSD-95 ( $n=10$ neurons from 2 experiments). C, Biochemical subfractionation of adult rat brain shows that GIPC is not enriched in PSD fractions, which are (Figure legend continues.) 
plex. Once internalized, GIPC reassociates with NMDA receptors and remains associated during recycling and exocytosis. The second model is more consistent with the idea that GIPC stabilizes NMDA receptors on the cell surface and is consistent with most current models on the functions of GIPC (Naccache et al., 2006). When GIPC is overexpressed, more receptor is present on the cell surface, whereas when GIPC is decreased by GIPC-DN or GIPCsiRNA, less receptor is on the surface. Therefore, removal of GIPC may be a prerequisite for internalization. The lack of a direct role for GIPC in endocytosis is supported by our internalization studies, because the GIPC-DN did not seem to affect the actual rate of internalization. If internalization of NMDA receptors depends on their interaction with another, yet unidentified PDZ protein, this model also would be consistent with GIPC serving an antagonist role, as discussed above.

\section{The NMDA receptor interacts with multiple $\mathrm{PDZ}$ proteins}

These findings add GIPC to the already large list of PDZ proteins that are reported to interact directly with the NR2 subunits of the NMDA receptor, including all four members of the PSD-95 family of MAGUKs (PSD-95, SAP102, PSD-93, SAP97), MAGI1-3, MALS1-3, and CIPP (Wenthold et al., 2003). Various explanations as to how multiple proteins could bind to the same site on the NMDA receptor have been suggested and include association with different subunits, different interactions during development, and associations with different stages of trafficking. Our results showing that GIPC is associated with a subset of receptors strengthens the case for the associations being dependent on stage of trafficking. An important remaining question is how the interaction of the NR2 subunits with PDZ proteins is regulated. PDZ interactions may be regulated by phosphorylation. Ser1480 (which is required for a PDZ interaction) of NR2B is phosphorylated by casein kinase II through an activity-dependent mechanism (Chung et al., 2004), leading to reversible disruption of the PDZ interaction. Although multiple PDZ proteins appear to control trafficking of NMDA receptors, GIPC also plays multiple roles in protein trafficking as described above. Therefore, GIPC, like several other proteins including GRIP, PICK1, and the MAGUKs, has multiple functions throughout many types of cells but is recruited to play a key role in receptor trafficking.

\section{References}

Alewine C, Olsen O, Wade JB, Welling PA (2006) TIP-1 has PDZ scaffold antagonist activity. Mol Biol Cell 17:4200-4211.

Aschenbrenner L, Lee T, Hasson T (2003) Myo6 facilitates the translocation of endocytic vesicles from cell peripheries. Mol Biol Cell 14:2728-2743.

Awan A, Lucic MR, Shaw DM, Sheppard F, Westwater C, Lyons SA, Stern PL (2002) 5T4 interacts with TIP-2/GIPC, a PDZ protein, with implications for metastasis. Biochem Biophys Res Commun 290:1030-1036.

\footnotetext{
$\leftarrow$

(Figure legend continued.) enriched in both PSD-95 and NR2B. GIPC is relatively abundant in the synaptic plasma membrane (SPM) fraction and P3, a fraction containing intracellular membranes. H, Homogenate; P, pellet; S, supernatant; LP, lysed pellet. $D, E$, Immunogold labeling (arrowheads) of native GIPC and PSD-95 at synapses in the CA1 stratum radiatum in the hippocampus of the adult rat. Data are presented as number of $10 \mathrm{~nm}$ gold particles found at the synapse, extrasynaptic membrane (Extra), and cytoplasm per synapse spine profile in a thin section (+SEM). For GIPC, extrasynaptic labeling was significantly greater than synapse labeling $\left({ }^{*} p<0.05\right)$. F, G, Distribution of flag-NR2B after cotransfection with GFP, GIPC, or GIPC-DN. GIPC-DN decreases surface NR2B (see Fig. 3). Quantification shows that GIPC-DN significantly increases the colocalization of flag-NR2B with bassoon. Data represent mean \pm SEM of the percentage of surface puncta for myc-NR2B that colocalized with bassoon compared with GFP ( $n=10$ neurons from 2 experiments; ${ }^{*} p<0.05$ ). For the immunofluorescence, hippocampus neurons 13 DIV were used. Scale bars: $A, F, 10 \mu \mathrm{m} ; \boldsymbol{D}, 100 \mathrm{~nm}$.
}

Barria A, Malinow R (2002) Subunit-specific NMDA receptor trafficking to synapses. Neuron 35:345-353.

Bashir ZI, Alford S, Davies SN, Randall AD, Collingridge GL (1991) Longterm potentiation of NMDA receptor-mediated synaptic transmission in the hippocampus. Nature 349:156-158.

Berretta N, Berton F, Bianchi R, Brunelli M, Capogna M, Francesconi W (1991) Long-term potentiation of NMDA receptor-mediated EPSP in guinea-pig hippocampal slices. Eur J Neurosci 3:850-854.

Blobe GC, Liu X, Fang SJ, How T, Lodish HF (2001) A novel mechanism for regulating transforming growth factor beta (TGF-beta) signaling. Functional modulation of type III TGF-beta receptor expression through interaction with the PDZ domain protein, GIPC. J Biol Chem 276:39608-39617.

Bunn RC, Jensen MA, Reed BC (1999) Protein interactions with the glucose transporter binding protein GLUT1CBP that provide a link between GLUT1 and the cytoskeleton. Mol Biol Cell 10:819-832.

Cai H, Reed RR (1999) Cloning and characterization of neuropilin-1interacting protein: a PSD-95/Dlg/ZO-1 domain-containing protein that interacts with the cytoplasmic domain of neuropilin-1. J Neurosci 19:6519-6527.

Chung HJ, Huang YH, Lau LF, Huganir RL (2004) Regulation of the NMDA receptor complex and trafficking by activity-dependent phosphorylation of the NR2B subunit PDZ ligand. J Neurosci 24:10248-10259.

Dance AL, Miller M, Seragaki S, Aryal P, White B, Aschenbrenner L, Hasson $\mathrm{T}$ (2004) Regulation of myosin-VI targeting to endocytic compartments. Traffic 5:798-813.

De Vries L, Lou X, Zhao G, Zheng B, Farquhar MG (1998) GIPC, a PDZ domain containing protein, interacts specifically with the $\mathrm{C}$ terminus of RGS-GAIP. Proc Natl Acad Sci USA 95:12340-12345.

Gao Y, Li M, Chen W, Simons M (2000) Synectin, syndecan-4 cytoplasmic domain binding PDZ protein, inhibits cell migration. J Cell Physiol 184:373-379.

Groc L, Heine M, Cognet L, Brickley K, Stephenson FA, Lounis B, Choquet D (2004) Differential activity-dependent regulation of the lateral mobilities of AMPA and NMDA receptors. Nat Neurosci 7:695-696.

Groc L, Heine M, Cousins SL, Stephenson FA, Lounis B, Cognet L, Choquet D (2006) NMDA receptor surface mobility depends on NR2A-2B subunits. Proc Natl Acad Sci USA 103:18769-18774.

Grosshans DR, Clayton DA, Coultrap SJ, Browning MD (2002) LTP leads to rapid surface expression of NMDA but not AMPA receptors in adult rat CA1. Nat Neurosci 5:27-33.

Harney SC, Rowan M, Anwyl R (2006) Long-term depression of NMDA receptor-mediated synaptic transmission is dependent on activation of metabotropic glutamate receptors and is altered to long-term potentiation by low intracellular calcium buffering. J Neurosci 26:1128-1132.

Hasson T (2003) Myosin VI: two distinct roles in endocytosis. J Cell Sci 116:3453-3461.

Hirakawa T, Galet C, Kishi M, Ascoli M (2003) GIPC binds to the human lutropin receptor (hLHR) through an unusual PDZ domain binding motif, and it regulates the sorting of the internalized human choriogonadotropin and the density of cell surface hLHR. J Biol Chem 278:49348-49357.

Jeanneteau F, Diaz J, Sokoloff P, Griffon N (2004a) Interactions of GIPC with dopamine D2, D3 but not D4 receptors define a novel mode of regulation of $G$ protein-coupled receptors. Mol Biol Cell 15:696-705.

Jeanneteau F, Guillin O, Diaz J, Griffon N, Sokoloff P (2004b) GIPC recruits GAIP (RGS19) to attenuate dopamine D2 receptor signaling. Mol Biol Cell 15:4926-4937.

Kedlaya RH, Bhat KM, Mitchell J, Darnell SJ, Setaluri V (2006) TRP1 interacting PDZ-domain protein GIPC forms oligomers and is localized to intracellular vesicles in human melanocytes. Arch Biochem Biophys 454:160-169.

Lavezzari G, McCallum J, Dewey CM, Roche KW (2004) Subunit-specific regulation of NMDA receptor endocytosis. J Neurosci 24:6383-6391.

Lin DC, Quevedo C, Brewer NE, Bell A, Testa JR, Grimes ML, Miller FD, Kaplan DR (2006) APPL1 associates with TrkA and GIPC1 and is required for nerve growth factor-mediated signal transduction. Mol Cell Biol 26:8928-8941.

Liu TF, Kandala G, Setaluri V (2001) PDZ domain protein GIPC interacts with the cytoplasmic tail of melanosomal membrane protein gp75 (tyrosinase-related protein-1). J Biol Chem 276:35768-35777.

Lou X, Yano H, Lee F, Chao MV, Farquhar MG (2001) GIPC and GAIP 
form a complex with TrkA: a putative link between $G$ protein and receptor tyrosine kinase pathways. Mol Biol Cell 12:615-627.

Montgomery JM, Madison DV (2002) State-dependent heterogeneity in synaptic depression between pyramidal cell pairs. Neuron 33:765-777.

Montgomery JM, Selcher JC, Hanson JE, Madison DV (2005) Dynamindependent NMDAR endocytosis during LTD and its dependence on synaptic state. BMC Neurosci 6:48.

Naccache SN, Hasson T, Horowitz A (2006) Binding of internalized receptors to the PDZ domain of GIPC/synectin recruits myosin VI to endocytic vesicles. Proc Natl Acad Sci USA 103:12735-12740.

O'Connor JJ, Rowan MJ, Anwyl R (1994) Long-lasting enhancement of NMDA receptor-mediated synaptic transmission by metabotropic glutamate receptor activation. Nature 367:557-559.

Osterweil E, Wells DG, Mooseker MS (2005) A role for myosin VI in postsynaptic structure and glutamate receptor endocytosis. J Cell Biol 168:329-338.

Perez-Otano I, Lujan R, Tavalin SJ, Plomann M, Modregger J, Liu XB, Jones EG, Heinemann SF, Lo DC, Ehlers MD (2006) Endocytosis and synaptic removal of NR3A-containing NMDA receptors by PACSIN1/syndapin1. Nat Neurosci 9:611-621.

Petralia RS, Wang YX, Mayat E, Wenthold RJ (1997) Glutamate receptor subunit 2-selective antibody shows a differential distribution of calciumimpermeable AMPA receptors among populations of neurons. J Comp Neurol 385:456-476.

Prybylowski K, Fu Z, Losi G, Hawkins LM, Luo J, Chang K, Wenthold RJ, Vicini S (2002) Relationship between availability of NMDA receptor subunits and their expression at the synapse. J Neurosci 22:8902-8910.

Prybylowski K, Chang K, Sans N, Kan L, Vicini S, Wenthold RJ (2005) The synaptic localization of NR2B-containing NMDA receptors is controlled by interactions with PDZ proteins and AP-2. Neuron 47:845-857.

Reed BC, Cefalu C, Bellaire BH, Cardelli JA, Louis T, Salamon J, Bloecher MA, Bunn RC (2005) GLUT1CBP(TIP2/GIPC1) interactions with GLUT1 and myosin VI: evidence supporting an adapter function for GLUT1CBP. Mol Biol Cell 16:4183-4201.

Roche KW, Standley S, McCallum J, Dune Ly C, Ehlers MD, Wenthold RJ (2001) Molecular determinants of NMDA receptor internalization. Nat Neurosci 4:794-802.

Rousset R, Fabre S, Desbois C, Bantignies F, Jalinot P (1998) The C-terminus of the HTLV-1 tax oncoprotein mediates interaction with the PDZ domain of cellular proteins. Oncogene 16:643-654.

Rumbaugh G, Vicini S (1999) Distinct synaptic and extrasynaptic NMDA receptors in developing cerebellar granule neurons. J Neurosci 19:10603-10610.

Sans N, Petralia RS, Wang YX, Blahos J, Hell JW, Wenthold RJ (2000) A developmental change in NMDA receptor-associated proteins at hippocampal synapses. J Neurosci 20:1260-1271.

Sans N, Prybylowski K, Petralia RS, Chang K, Wang YX, Racca C, Vicini S, Wenthold RJ (2003) NMDA receptor trafficking through an interaction between PDZ proteins and the exocyst complex. Nat Cell Biol 5:520-530.

Scott DB, Michailidis I, Mu Y, Logothetis D, Ehlers MD (2004) Endocytosis and degradative sorting of NMDA receptors by conserved membraneproximal signals. J Neurosci 24:7096-7109.

Snyder EM, Philpot BD, Huber KM, Dong X, Fallon JR, Bear MF (2001) Internalization of ionotropic glutamate receptors in response to mGluR activation. Nat Neurosci 4:1079-1085.

Sucher NJ, Brose N, Deitcher DL, Awobuluyi M, Gasic GP, Bading H, Cepko CL, Greenberg ME, Jahn R, Heinemann SF, Lipton SA (1993) Expression of endogenous NMDAR1 transcripts without receptor protein suggests post-transcriptional control in $\mathrm{PC} 12$ cells. J Biol Chem 268:22299-22304.

Thomas CG, Miller AJ, Westbrook GL (2006) Synaptic and extrasynaptic NMDA receptor NR2 subunits in cultured hippocampal neurons. J Neurophysiol 95:1727-1734.

Tovar KR, Westbrook GL (1999) The incorporation of NMDA receptors with a distinct subunit composition at nascent hippocampal synapses in vitro. J Neurosci 19:4180-4188.

Tovar KR, Westbrook GL (2002) Mobile NMDA receptors at hippocampal synapses. Neuron 34:255-264.

Vanhoutte P, Bading H (2003) Opposing roles of synaptic and extrasynaptic NMDA receptors in neuronal calcium signalling and BDNF gene regulation. Curr Opin Neurobiol 13:366-371.

Varsano T, Dong MQ, Niesman I, Gacula H, Lou X, Ma T, Testa JR, Yates III JR, Farquhar MG (2006) GIPC is recruited by APPL to peripheral TrkA endosomes and regulates TrkA trafficking and signaling. Mol Cell Biol 26:8942-8952.

Wang LH, Kalb RG, Strittmatter SM (1999) A PDZ protein regulates the distribution of the transmembrane semaphorin, M-SemF. J Biol Chem 274:14137-14146.

Wenthold RJ, Prybylowski K, Standley S, Sans N, Petralia RS (2003) Trafficking of NMDA receptors. Annu Rev Pharmacol Toxicol 43:335-358.

Yano H, Ninan I, Zhang H, Milner TA, Arancio O, Chao MV (2006) BDNFmediated neurotransmission relies upon a myosin VI motor complex. Nat Neurosci 9:1009-1018. 